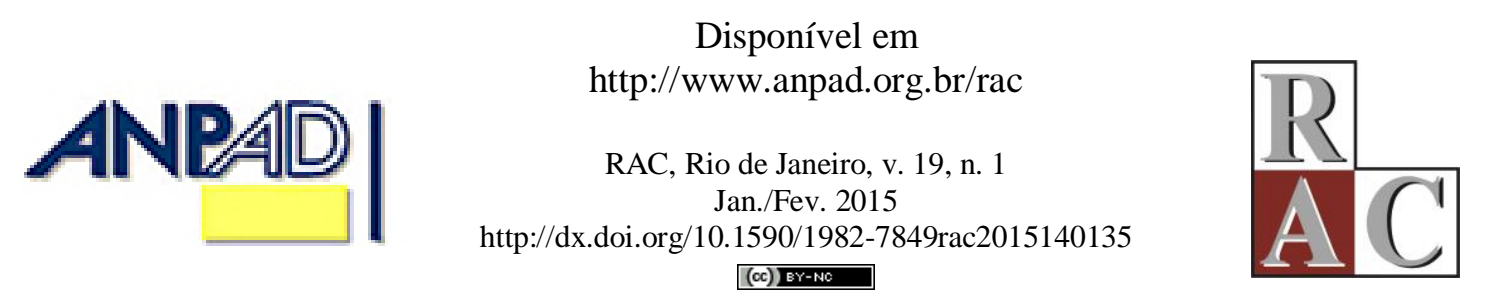

\title{
Desafios da Editoração de Periódicos Científicos no Brasil
}

\author{
Herbert Kimura \\ Universidade de Brasília - UnB \\ Editor-chefe da RAC
}

Conforme já indicado em outros documentos disponibilizados como Carta ao Leitor, o mercado de editoração científica no Brasil está passando por diversas mudanças. Se, até algum tempo atrás, as transformações eram mais silenciosas, o final de 2014 foi marcado por sinalizações mais contundentes, que têm gerado um debate agora um pouco menos tímido.

Mais particularmente, dois eventos podem ser citados para fundamentar o argumento de importantes alterações na dinâmica de periódicos científicos no Brasil: a proposta da CAPES em bancar a publicação de revistas nacionais por editoras internacionais, e os novos critérios para admissão e permanência de periódicos na coleção SciELO.

A reunião da CAPES com editores de periódicos nacionais e com representantes de publishers internacionais em outubro de 2014 causou uma discussão intensa na comunidade. Na reunião, a CAPES informou sobre o planejamento de dois editais. O primeiro edital estaria voltado para a seleção de publishers que auxiliariam periódicos nacionais a avançarem na profissionalização e na internacionalização. $\mathrm{O}$ segundo edital selecionaria as revistas nacionais que receberiam suporte financeiro para disponibilizar seus artigos nas plataformas desses publishers. Assim, um processo de divulgação com abrangência internacional poderia gerar maior exposição e maior impacto global das pesquisas publicadas nas revistas brasileiras.

Informações sobre esse evento podem ser encontradas na Carta ao Leitor publicada na edição 18.6 da RAC, em 2014. É importante enfatizar que essa iniciativa da CAPES encontrou tanto apoiadores quanto críticos. Independentemente da perspectiva, a favor ou contra a proposta da CAPES, existe uma movimentação consistente na busca de melhores indicadores para a produção científica nacional.

Nesse contexto, o SciELO, em documento de setembro de 2014, estabeleceu novas políticas e procedimentos associados à indexação nessa plataforma. Dentro do planejamento do SciELO, existem três ações consideradas prioritárias para os periódicos científicos nacionais: profissionalização, internacionalização e sustentabilidade financeira.

Dentre essas ações, os novos requisitos do SicELO representam, particularmente os relacionados à internacionalização, desafios importantes para os quais a maioria dos periódicos das áreas de Administração e Contabilidade, incluindo-se a RAC, ainda têm um caminho a percorrer. Por exemplo, os periódicos terão que obedecer a certos critérios mínimos de porcentagem de editores associados, de revisores e de autores com afiliação estrangeira. Além disso, há definição de uma parcela mínima de artigos a serem publicados no idioma inglês pelos periódicos. 
Para o SciELO, essas iniciativas voltadas à internacionalização permitirão maior visibilidade, gerando uma quantidade maior de citações de artigos de periódicos da coleção. A despeito de o atendimento a esses requisitos de internacionalização não ser imediato, os periódicos que pretendem ser incluídos ou que desejam se manter na plataforma SciELO devem já iniciar um planejamento para a adequação ao novo ambiente.

Além disso, outros pontos de atenção mais prementes foram definidos pelo SciELO e já estão sendo contemplados ou incorporados pela RAC. Por exemplo, a partir de 2015, o SciELO exige que todos os artigos publicados pelos periódicos da coleção utilizem marcação XML para automatizar o levantamento de elementos bibliográficos, bem como para viabilizar a disponibilização dos artigos em diversos formatos, inclusive para dispositivos móveis. Todos os periódicos deverão também ser gerenciados por meio de sistemas de editoração online. Destaca-se que a RAC, já a partir de julho de 2014, tem gerado arquivos em conformidade com o formato do XML-SciELO. Adicionalmente, o periódico migrou do Open Journal System para o ScholarOne Manuscripts, visando à maior agilidade no processo de submissão e no acompanhamento de avaliações.

É importante estabelecer que a velocidade do fluxo editorial depende não somente de sistemas automatizados, como também de melhoria de eficiência de processos da equipe editorial, de autores e de avaliadores. Assim, avanços relevantes devem ser empreendidos para que a comunidade entenda que autores e avaliadores possuem responsabilidade para o aprimoramento das métricas dos journals.

Tendo em vista que os diversos desafios impostos pelas alterações do mercado de periódicos científicos exigem capacitação e profissionalização da equipe, os periódicos da ANPAD estiveram presentes em eventos como, por exemplo, os da ABEC e os do SciELO. No XXII Curso de Editoração Científica, em maio de 2014, foram abordados temas diretamente ligados ao processo editorial, como, por exemplo, o idioma de publicação, a obtenção de revisões construtivas, o envolvimento de pareceristas, a detecção de plágio, etc...

No VIII Workshop de Editoração Científica promovido pela ABEC, a equipe editorial teve a oportunidade de participar de minicursos, compartilhar experiências com outras equipes e vislumbrar tendências no segmento, apresentadas por profissionais brasileiros e estrangeiros. Nesses eventos, há diversos representantes de periódicos de áreas que estão mais avançadas no processo editorial científico e, dessa maneira, a troca de informações é extremamente enriquecedora. Finalmente, na IV Reunião Anual do SciELO, foram apresentados diversos indicadores da produção científica nacional, bem como as orientações que estão sendo definidas para que artigos dos periódicos brasileiros tenham maior impacto na comunidade internacional.

Em um contexto em que as mudanças no segmento de periódicos científicos trazem também questões referentes à sustentabilidade financeira, a RAC tem a satisfação de informar a obtenção de recursos em chamada de 2014 do MCTI/CNPq/MEC/CAPES para apoio à editoração de periódicos. Parte dos valores desse apoio financeiro será utilizada para aperfeiçoamento da revista, principalmente em relação a aspectos de formatação e disponibilização de conteúdo, com o objetivo de conferir maiores visibilidade, influência e impacto.

Em particular, tendo sido contemplada também com recursos na chamada de editoração de 2013, a RAC iniciou o projeto de marcação XML não somente para atender às novas exigências do SciELO, como também para estabelecer as bases de um sistema que permita a geração de algumas métricas de impacto de artigos, autores, periódicos, instituições.

Nesse sentido, antecipando obstáculos para integração e compilação de dados, alguns itens, embora possam parecer meros detalhes, são relevantes, dentro de uma perspectiva de internacionalização da produção nacional. Por exemplo, a existência do Digital Object Identifier (DOI) de cada trabalho é fundamental para a captura automática de dados bibliográficos. Destaca-se que todos os periódicos da coleção SciELO possuem DOI.

Além disso, outro detalhe importante é a necessidade de o autor estabelecer um padrão para referências a seus trabalhos. Benson e Silver (2013) alertam para o fato de que nomes de autores 
representam fonte de confusão comum, fazendo com que editores tenham grande dificuldade em reproduzir e indexar adequadamente essas informações, principalmente quando não seguem convenções usuais.

Se, quando o artigo é direcionado ao público brasileiro, a preocupação com o nome pode não ser grande, ao buscar leitores em outros lugares do mundo, a notação pode fazer diferença. Abordagens distintas em relação à ordem entre nome e sobrenome, à acentuação dos nomes próprios ou à inclusão de sufixos como Filho e Neto, podem implicar diferentes métricas de produtividade de um determinado autor. No caso de autores brasileiros, Benson e Silver (2013) citam explicitamente que a existência de múltiplos sobrenomes pode levar a problemas ou inconsistências nas bases de autores. Nesses casos, métricas do autor podem ficar comprometidas como, por exemplo, o índice $h$.

O índice h, sugerido por Hirsch (2005), é uma medida que reflete a produção e o impacto de um autor, levando em consideração as citações de seus artigos. De acordo com Hirsch (2005), um pesquisador possui um índice $\mathrm{h}$ se, dentre seus $\mathrm{N}$ artigos, um número $\mathrm{h}$ deles recebe um mínimo de $\mathrm{h}$ citações, sendo que os outros $\mathrm{N}$-h artigos não possuem, individualmente, mais de $\mathrm{h}$ citações. Assim, a identificação consistente do nome do autor torna-se necessária.

Assim, o acompanhamento de métricas depende não somente da adequada marcação XML, como também da padronização, por parte do autor, de suas informações. Esse procedimento de uniformização de dados permitirá, também, que trabalhos do autor sejam melhor rastreados em medidas alternativas como as Altmetrics, ou seja, indicadores baseados em web e calculados a partir de plataformas de mídia social como, por exemplo, Twitter e Mendeley (Bornman, 2014).

Como o leitor pode perceber, as mudanças no mercado de editoria científica trazem também desafios aos próprios autores e pesquisadores. Esperamos a todos que o ano de 2015 seja profícuo e produtivo.

\section{Referências}

Benson, P. J., \& Silver, S. C. (2013). What editors want: an author's guide to scientific journal publishing. USA: The University of Chicago Press.

Bornmann, L. (2014). Do altmetrics point to the broader impact of research? An overview of benefits and disadvantages of altmetrics. Journal of Informetrics, 8(4), 895-903. doi: 10.1016/j.joi.2014.09.005

Hirsch, J. E. (2005). An index to quantify an individual's scientific research output. Proceedings of the National Academy of Sciences of the United States of America, 102(46), 16569-16572. doi: 10.1073/pnas.0507655102

\section{Dados do Autor}

Herbert Kimura

Prédio da FACE, Sala A1-82-7, Campus Universitário Darcy Ribeiro, 70910-900, Brasília, DF, Brasil. E-mail: rac.herbert.kimura@gmail.com 